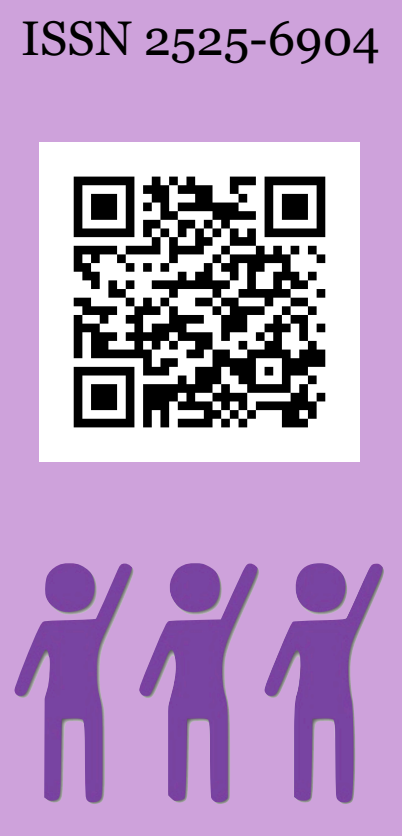

MULHERES COM PARTIDO

\title{
Mulheres na Política
}

\section{Entrevista com a vereadora Sandra Marrocos, João Pessoa/PB}

Amanda Christinne Nascimento MARQUES, Universidade Federal da Paraíba Vivianne de SousA, Universidade Federal de Campina Grande

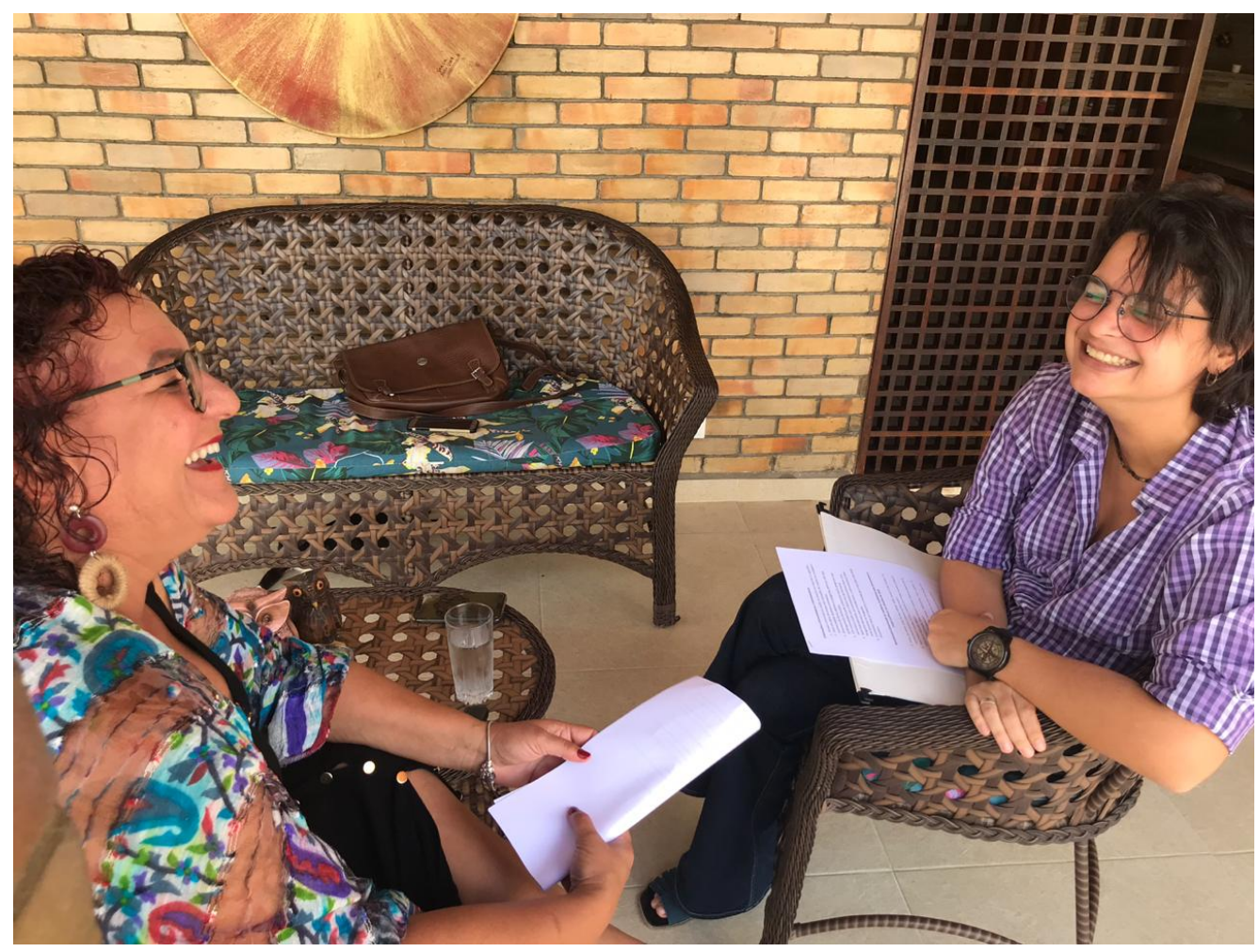

(D)) \# PraCegoVer: Nessa foto, vemos duas mulheres durante entrevista. 4D)) Todas sorriem. Da esquerda para a direita estão Sandra Marrocos e Amanda Marques. 
Em 22 de novembro de 2018, na cidade de João Pessoa/PB, entrevistamos a vereadora Sandra Marrocos (PSB) com o propósito de dialogarmos sobre as relações entre gênero e política, momento em que a entrevistada fez um relato da sua trajetória de vida, nos movimentos sociais e afirma a importância de termos mulheres ocupando cargos no Legislativo brasileiro.

Fomos recebidas em sua casa durante o período da manhã e, sob um clima de muita descontração e receptividade, a vereadora e sua equipe de assessores nos presenteou com uma boa conversa.

Nascida em Curral Velho, alto sertão paraibano, Sandra Marrocos migrou para João Pessoa aos dez anos de idade. Filha de Jandira Marrocos, funcionária pública e José Silvino, agricultor, Sandra inicia sua atuação política ainda muito jovem dada sua participação nas pastorais de base da igreja católica, no movimento estudantil secundarista e, posteriormente, universitário.

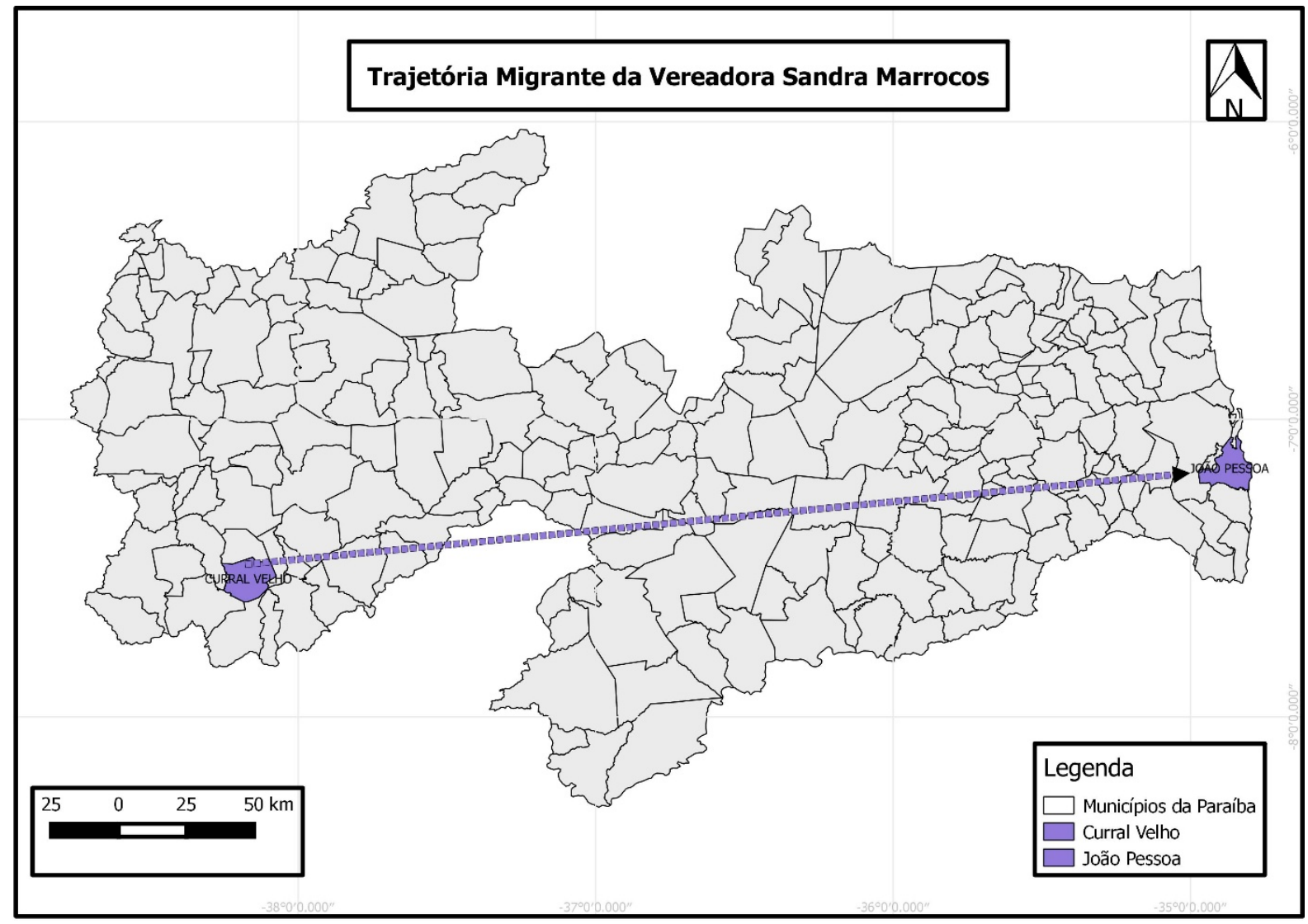

Fonte: Elaboração própria (2018). 
Como estudante do curso de Serviço Social, foi assessora do hoje governador do Estado da Paraíba, Ricardo Coutinho (PSB), com o qual, durante os anos de 1990, fez parte da base do Partido dos Trabalhadores (PT). Atualmente, aos 47 anos, Sandra representa a base do PSB na câmara de vereadores de João Pessoa, estando em seu segundo mandato.

A vereança significa para Sandra uma maior atuação nos espaços públicos e nas tomadas de decisão, sobremaneira pelo seu autorreconhecimento como feminista. A vereadora compreende que, para mudar as lógicas históricas do patriarcado, é preciso ter voz ativa e ocupar esses espaços.

A seguir, apresentamos às leitoras e leitores nossos diálogos com Sandra Marrocos:

Pergunta: Conte um pouco como foi sua infância. Onde nasceu? Onde morava? Um acontecimento histórico ou pessoal que lhe marcou?

Sandra Marrocos: Sou sertaneja, não sei se você sabe. Nasci lá em Curral Velho, no Alto Sertão da Paraíba. Numa cidade bem pequenininha, acho que tinha apenas quatro ruas. Minha mãe era uma mulher bem forte. Hoje, que eu consigo fazer a leitura de gênero e a percebo naquele momento histórico. Ela tinha um cartório e meu pai era um trabalhador rural. Fiquei no sertão até os 9 anos. Vim embora para João Pessoa com 10 anos. Minha infância foi uma delícia, solta na rua, numa cidade que todo mundo se conhecia. Eu sou a décima filha, minha mãe teve cinco homens e cinco mulheres, todos nascidos na cama dela. Eu nasci na cama da minha mãe! Ela adotou a filha de uma outra irmã. Então nos tornamos seis mulheres e ela ainda cuidou de três sobrinhos, filhos de minha tia que partiu cedo. Então uma coisa que me marca na infância, apesar dela ter sido recheada de felicidade, foi isso, de eu ser a mais nova, ou seja, era alguém que era cuidada por muita gente, por todo mundo! Eu tinha irmã com o dobro da minha idade, a menor diferença era de seis anos pra mim. Quando me teve minha mãe nem pensava mais em engravidar, ela tinha 42 anos!

A minha saída do sertão também me marcou muito. Foi uma saída sem a despedida dos meus brinquedos, das minhas amigas, dos meus amigos. Não fiz a despedida como ela devia ter sido feita. Eu vim para João Pessoa sozinha. Meu tio era fiscal da Patoense, que ia para 
Patos, e ele me trouxe para João Pessoa. Eu cheguei aqui aos 10 anos. O importante é que a minha infância foi livre e feliz! No meio da rua, correndo o tempo inteiro. Era ótimo! Acho que a minha liberdade vem dali, sabia? Daquele momento... Fui criada livre!

Pergunta: Quais foram os conceitos, normas e costumes que recebeu durante a infância? Como foi sua educação religiosa?

Sandra Marrocos: Minha filha disse que eu consegui romper com os valores da minha família, que era de raízes coronelistas. Meu avô era Coronel, Coronel Zuza Lacerda, tanto que tem uma igreja vizinha à casa dele. Minha família vem de uma relação machista, coronelista, com as pessoas dizendo que o papel da mulher era estar no espaço privado. Mas eu tive minha mãe que foi um grande diferencial na minha vida.

Antes de minha mãe ir para o Sertão, ela estudou aqui em João Pessoa. Quando ela chegou lá, era a "moderna". Por isso, apesar de termos nos criado naquele espaço, hoje consigo conquistar o respeito de meus irmãos e irmãs, mesmo nossos valores tendo sido aqueles de sempre, que o lugar da mulher era ali, no privado. Minha mãe foi uma feminista de atitude, porque enquanto as mulheres ficavam na cozinha, ela ficava no cartório, ela datilografava... O tempo inteiro ela escrevia, o tempo todo ela estava no espaço público. Como minha mãe ficava o tempo inteiro no cartório e meu pai trabalhava na roça onde tinha um monte de gente que ajudava, acabei criada numa casa de taipa bem simples por um monte de babás, mãe Nena, Bibida, mulheres negras, mulheres fortes! Eu passava o tempo inteiro lá.

Recebi os valores religiosos, como os da primeira Eucaristia, mas lembro que sempre fui muito questionadora. $\mathrm{O}$ padre sempre almoçava lá em casa. Todo mundo comia lá em casa! A casa inteira era cheia. Agora na campanha recebi um depoimento lindo, uma mulher disse que aquilo tudo que acontecia na casa da minha mãe era uma preparação de Deus. Os costumes que recebi na infância foram conservadores, patriarcais, coronelistas, mas essa figura da minha mãe, que se diferenciava das demais mulheres, foi uma inspiração. Nossa religiosidade era cristã, católica, que muita gente termina tendo, mas minha mãe não era muito beata de igreja. Uma vez eu pintei a igreja de lilás. Então rompi com isso, graças à figura fantástica da minha mãe, uma mulher forte que se colocava o tempo todo. 
Pergunta: Fale sobre a sua formação. Onde começou a estudar? Quais as pessoas que te marcaram durante sua vida escolar? Quais eram seus ideais? Que pessoas influenciaram você positiva ou negativamente?

Sandra Marrocos: Você já percebeu que minha mãe me marcou demais. Eu estudava na Escola Coronel Zuza Lacerda, a escola com o nome do meu bisavô. Muita gente estudava lá. Eu lembro de várias. Tinha uma senhora chamada Madrinha. Outra pessoa que me marcou foi Mobral. Só depois descobri que o nome dela não era Mobral, mas eu a chamo de Mobral até hoje. Ela era chamada assim porque não tinha curso para alfabetizar adultos, e era ela que alfabetizava. Então as mulheres fortes sempre me chamaram atenção, mesmo sem eu saber o porquê.

Minha mãe, como trabalhava o dia inteiro, não queria que a gente ficasse nas ruas. Então frequentávamos o reforço escolar de uma mulher chamada Madrinha Loura. Aí eu estudava de manhã no grupo e de tarde na casa de Madrinha Loura. Ela é viva até hoje! Nós ficávamos lá fazendo as aulas de reforço, era quase uma escola em tempo integral.

Então eu vim para João Pessoa e continuei os estudos. Morei com minhas irmãs e a casa continuou cheia de mulheres. Na minha vida familiar, as mulheres sempre se colocaram. Em João Pessoa estudei, inicialmente, em uma escola que hoje virou uma clínica. Descobri quando eu subi as escadas para fazer uns exames. A escola se chamava Nossa Senhora de Lourdes. De lá, a gente foi morar em Santa Rita, e estudei no Instituto Santa Terezinha, que era privado também. Minhas irmãs pagavam as contas, já que eu era a menorzinha. Estudei no colégio Nossa Senhora das Neves e depois, com o tempo, as dificuldades aumentaram, economicamente falando.

Minha mãe veio morar aqui na periferia quando ainda não tinha se aposentado. Passamos por muitas dificuldades, não sei como a gente sobreviveu. Aí fui estudar no Colégio Estadual de Jaguaribe.

Vou contar uma coisa que nunca contei para ninguém. Eu perdi um ano escolar, e não foi porque eu não queria estudar, mas porque eu sempre quis estudar muito. Tinha gente que achava que eu não passava de uma perda de tempo. Brigavam comigo porque eu estudava. Não consegui concluir porque a escola era em Jaguaribe e eu morava no Ernany Sátiro, e não tínhamos dinheiro para passagem. Eu tive que abandonar no final, foi horrível! Aí fui transferida para o Osvaldo Pessoa, 
que era perto da minha casa. Lá estudei um ano e depois mudei parao Lyceu Paraibano. aí tinha o Setusa, que foi a única estatal que prestou serviço de transporte público em João Pessoa, por isso que esse tipo de transporte é fundamental! $O$ estudante não pagava e assim não perdi mais aula, usava farda... Essa história de eu ter tido que abandonar foi por isso. Faço sempre a leitura das relações econômicas quando falo do meu desejo pessoal de estudar. O Setusa marcou muito a minha vida, porque possibilitava que eu chegasse ao ambiente escolar. Isso era muito bom! De ter perdido um ano, o Setusa possibilitou que eu estudasse no Lyceu, onde entrei para o Grêmio. Depois me casei e engravidei, uma "doidiça" grande na minha vida!

Pergunta: Como descreve política e socialmente o Estado em que vive e sua relação com o restante do país?

Sandra Marrocos: Eu avalio que a Paraíba, nesse nosso tempo histórico, vive uma coisa diferenciada do país. Estou com o Ricardo Coutinho, desde que ele era vereador. Quando Lula foi eleito, o Brasil viveu a primeira experiência democrática no campo popular, logo depois, Ricardo Coutinho foi eleito em João Pessoa. Então João Pessoa passou a viver essa experiência. Já no governo Dilma aconteceu o golpe misógino, sem nada que comprovasse juridicamente que ela teria que sair dali. Tudo bem preparado. Eu estava vereadora entre 2008 e 2012, e entrava em pânico, porque via o pessoal conservador assumir os parlamentos. Nós ainda estávamos encantados porque tínhamos ocupado os lugares de poder na democracia representativa do país, inclusive na nossa cidade. E eles estavam se organizando para tomar o parlamento e foi isso que aconteceu. Só que aqui na Paraíba Ricardo Coutinho vence a eleição, mas a experiência foi completamente diferenciada.

Estou muito angustiada desde o fim da eleição presidencial de 2018, pois não consigo avaliar com clareza o que teremos a partir de janeiro. Avalio com clareza o que a gente tem hoje, que é um governo ilegítimo que retira direitos. Mas a Paraíba tem uma reação, que é o governo do campo democrático e popular. Avalio também que precisamos montar estratégias de enfrentamento institucional para garantir direitos. Uma das coisas que precisamos fazer fortemente, principalmente quem está nos espaços de parlamento, quem está vivenciando o espaço executivo, como o Ricardo Coutinho e o João 
Azevedo, é reagir. Pois o que vem por aí dará continuidade, por exemplo, nessa história do escola sem partido.

Nós temos que nos posicionar como o Ricardo se posicionou, como os governadores do Nordeste se posicionaram. Dizendo não, que a liberdade de cátedra vai prevalecer, que a educação tem que prevalecer com o pluralismo de ideias e o ensino com criticidade. Isto é, fazer falas na câmara, colocar marcos legais regulatórios... Dei entrada em um projeto de autoria nossa sobre a democratização do ensino no município de João Pessoa, que segue tramitando. Ontem inclusive fiz uma fala sobre isso. Temos que montar uma estratégia em termo dos marcos legais regulatórios, dizer que a democracia está aí, que é um campo fértil para a gente garantir os direitos, para reafirmar direitos e buscar estratégias de enfrentamento público. Não visualizo hoje uma grande manifestação. Esse é o momento da gente se juntar e ir montando estratégias de enfrentamento. E hoje acho que tenho a sorte e a oportunidade de vivenciar um governo em um estado que se coloca diferente do que vai acontecer no país a partir de janeiro, isso é bom e importante.

Pergunta: Como a política entrou em sua vida, ou como você entrou na vida política?

Sandra Marrocos: Quando vim morar aqui, vivenciei um contexto de pobreza muito forte, como eu já falei. Naquele momento, dois movimentos estavam acontecendo: os "ranchos", que eram as matinês e tinha a "igreja católica" com a teologia da libertação, fundando as pastorais e fazendo a intervenção. Eu morava nesse contexto de pobreza, onde as meninas eram fortemente atraídas para os ranchos, para a liberdade. A minha situação de pobreza me fez perceber que se eu me juntasse com outras pessoas, ia conseguir mudar a minha realidade e a realidade em que estava inserida.

A minha primeira experiência de construção coletiva política foi na igreja católica com as pastorais. Nos juntamos e questionávamos por que tudo aquilo acontecia. Por que eu me juntei com os ranchos? Descobri que estava forte, e muitas das minhas amigas de adolescência se perderam na vida, não estudaram, ficaram só nessa história da diversão, mas consegui fazer essa junção. No mesmo período, acontecia 
o movimento estudantil secundarista e fui do grêmio do Lyceu Paraibano.

Me casei muito jovem, engravidei e fui mãe aos 20 anos. Tenho 3 filhos, uma menina e dois meninos. Continuei militando na igreja, no movimento estudantil, nunca parei de estudar. Terminei no Lyceu grávida de Janaina, não passei no primeiro vestibular e quando fiz o vestibular de novo, estava grávida do Flávio, aí eu passei.

A política entra automaticamente na vida das pessoas que questionam. Na universidade já entrei no centro acadêmico, na Pastoral da Perseverança, na praia do Poço, onde eu morava, e fiz a ruptura do primeiro casamento. Para isso tive dois encontros que foram muito importantes na minha vida política, um deles foi com o feminismo. Fui estagiar no Centro "Acorda Mulher" e ali me descobri feminista. Até então, apesar de ocupar espaços de poder, de questionar várias coisas que eu via, dentro e fora da minha casa, não sabia direito por que eu fazia aquilo tudo. Me descubro feminista e me separo nesse momento. E aí fui trabalhar com o Ricardo Coutinho como assessora, quando ele foi deputado. Eu tinha a tarefa de fazer a ponte dos movimentos sociais com o mandato. Já era do movimento feminista, saí da Pastoral da Juventude, do Meio popular. Nesse momento ganhamos a prefeitura. Além disso, passo no mestrado. Minha formação é em Serviço Social e passei no mestrado bem na época que Ricardo foi candidato a prefeito. Eu que coordenei a mobilização da campanha dele, com 27 anos, ainda bem despreparada. Ganhamos e começamos essa experiência de democracia participativa. Se eu fechar o olho, vejo a cidade todinha, pois já fui em todos os locais de João Pessoa.

Em 2008, as pessoas começaram a colocar o meu nome como candidata. Aprendi muito cedo a fazer as coisas coletivamente e então construímos um grupo chamado "Coletivo de Todas as Lutas", que fundou o bloco "Mulher de Luta", que já está na sua décima primeira edição. Conseguimos me eleger vereadora na primeira vez e, a partir de então, percebi que a política você não sabe como entra e não consegue sair. Primeiro porque não quero, porque acho importante, apesar de muito desgastante para a vida pessoal. Perdi um mandato em 2012, fui a décima sétima mulher mais bem votada, mas não fui eleita.

Entrei na política naturalmente, não planejei ser candidata a deputada federal, só agora, por duas questões. Primeiro pelas mulheres. Quando mataram Marielle tomei a minha decisão. Não tínhamos 
dinheiro, mas decidimos tentar. Eu pensava, "se eu tiver um voto vai ser de luta". Tivemos 23 mil votos, 23 mil pessoas nesse estado, com votação em 210 municípios. Então entrar na política, com os votos que tive, é consequência da minha história. Tive dois mandatos como eleita, em 2012 fiquei na primeira suplência, dez homens entraram e ninguém do campo democrático e eu ainda entrei por um ano! Nesse período passei dois anos na Política da Socioeducação do Estado, uma experiência muito forte, uma política bastante complexa. Nessa época, 17 adolescentes das unidades de medida socioeducativa, privados de liberdade, passaram no vestibular, garantimos a ida de todos para a universidade.

Pergunta: Por quais partidos já passou?

Sandra Marrocos: PT e PSB.

Pergunta: Quais as pautas que defende na política?

Sandra Marrocos: As mulheres e a pauta feminista estão inseridas em todas as minhas ações. Sei que estou por todos e todas, mas estou principalmente pelas mulheres. Algo que temos que defender com todas as forças é o Estado democrático de direito, é a democracia e, a partir daí, vai para todas as pautas que nós defendemos: a cidadania das mulheres, dentro da cidadania o combate à violência contra a mulher. Nós temos uma lei pioneira no país, que é a Lei Marielle Franco, que diz que, em todas as escolas públicas e privadas, deverão ensinar as noções básicas da Lei Maria da Penha. É uma coisa nossa, do nosso mandato. Na minha avaliação, depois da Lei Maria da Penha, é a maior ferramenta de combate à violência contra a mulher, porque ela vai lá na raiz. Tem a cidadania LGBT fortalecida, pois o que me deixa indignada, porque a sua orientação sexual e sua religião é do foro íntimo, e enquanto ser humano, acho repugnante quando vejo ódio sendo plantado contra as pessoas LGBT's, pois o ódio acarreta no assassinato. Conseguimos algo maravilhoso que foi a criação da Coordenadoria da Cidadania LGBT e Igualdade Racial, que hoje é uma ferramenta do governo, que foi pautada e discutida dentro do nosso mandato. Pautamos a diversidade 
em um mandato coletivo, por todas as lutas e as pessoas em situação de pobreza, a questão da moradia...

Pergunta: O que significa estar na vida político-partidária?

Sandra Marrocos: Sou dirigente nacional e municipal do PSB, e fui dirigente no PT. Tem uma coisa que nós temos usado muito que é a sororidade, e não adianta olhar para as mulheres do meu lugar de hoje, tenho que olhar para as mulheres, inclusive a partir da minha experiência individual, da Sandra de antes e de hoje. Hoje tenho meu espaço garantido, é um espaço difícil, pois é um lugar hegemonicamente de homens, por mais que queiram dizer o contrário. Para mim é desafiante, mas se pudesse, um maior número de mulheres ocupariam esse espaço. É de lá, do partido político, que a gente pode chegar lá. Precisamos ser de um partido para se candidatar a deputada, vereadora.

Com o fundo partidário, pela primeira vez, conseguimos fazer uma campanha tranquila. Sabemos que a gente pode fazer, pois a nossa fortaleza é a nossa história, mas o fundo partidário garantiu fazer um material de campanha massa, pois é o que a gente tem. O dinheiro veio como fruto da nossa luta e deu para fazer um bom material, junto com os $30 \%$ da cota das mulheres. Isso foi fundamental para conseguirmos os 23 mil votos, pois a grande dificuldade das mulheres nos partidos é a falta de incentivo estrutural para as candidaturas. Eu gostaria de ter mais tempo, de ter outra função, fui secretária das Mulheres no PSB e a gente puxava muito o processo de discussão para fortalecer a pauta. É um espaço difícil, mas precisa ser ocupado.

Pergunta: Acha que há machismo na política? Quais as estratégias utilizadas por você para lidar com situações de machismo na política e no cotidiano da vida pública e privada?

Sandra Marrocos: Existe machismo na sociedade, a minha casa é um espaço que a gente busca descontruir o machismo todo o tempo, mas a nossa sociedade é feita também de machismo e o nosso processo é de desconstrução. Como tenho clareza de onde estou e quem represento, vou para o enfrentamento, pelas mulheres. É uma história 
pesada. Os homens, quando gritam, são fortes. Nós, quando gritamos, somos doidas, histéricas. Mas saibam que se precisar serei a mais doida de todas! Nesse momento enfrento com diálogo, com fala pública. Tentam tirar o nosso microfone. O tempo inteiro existe uma armação para que sejamos silenciadas, não estejamos nas mesas... Precisamos de atitude sempre.

Pergunta: O Brasil vivenciou momentos tensos durante o último pleito presidencial. Conte-nos como experienciou este momento significativo para a história do país?

Sandra Marrocos: Estive na resistência, inclusive enquanto candidata. Queria ter sido eleita, porque estive na arena de enfrentamento na campanha por ter uma fala que nos representasse enquanto mulheres e pela necessidade de ter no nosso palanque uma fala que nos representa. Participei desse momento fazendo campanha do primeiro ao último dia, sem parar, pois o que a gente vive nesse país não é uma disputa de eleição, é uma disputa de projeto de sociedade. Nesse momento sou resistência, queria ser resistência com o poder de fala em Brasília, mas temos a arena de João Pessoa. Essa foi uma campanha serena, apesar de tudo, porque sei o meu papel na garantia de direitos e eu não "arredo" um centímentro.

Pergunta: Como encara o debate sobre gênero e sexualidade tão reivindicado e usado nos últimos anos no cenário político brasileiro?

Sandra Marrocos: O Estatuto da Família, a Escola Sem Partido, foram processos construídos. Pegando o Estatuto da Família, por exemplo, nunca me senti tão ofendida, pois toda vez que queria bater, a intenção deles é bater na cidadania LGBT. Mas antes disso batem fortemente nas mulheres, pois quando dizem que a família é formada por homem, mulher e filhos biológicos, então existe uma criminalização de outros modelos de família, que eu mesma não me adequo. Todos os dias falo sobre isso na tribuna da câmara, porque essa história de criminalizar o estudo e o conceito de gênero foi para bater na Cidadania LGBT. Aconteceu quando as identidades de gênero se fortaleceram. A gente se colocou, dizendo que quando você bate no 
conceito de gênero, você bate nas mulheres. Os Estudos de Gênero garantem que as diferenças entre homens e mulheres sejam estudadas, colocadas e dentro delas as políticas públicas de saúde, por exemplo. Temos que dizer que a ideologia de gênero não existe, que o que existe é a criminalização e o extermínio de um projeto de sociedade. Estamos constantemente lutando contra a erotização das crianças. Tem uma lei da nossa autoria que diz que nenhuma música, letra ou coreografia que desqualifique ou incite a violência contra a mulher ou coloque ela em situação vexatória, deve ser contratada no Município de João Pessoa. É um enfrentamento ao estupro e à violência sexual. Por fim, nós e a academia temos um papel fundamental para falarmos diretamente com o povo.

Pergunta: Você acha que o discurso do presidente eleito autorizou ações violentas sobre o corpo da mulher, dos LGBTQI+, dos negros/as, nordestinos/as?

Sandra Marrocos: Completamente, pois política é atitude, é lei, é incentivo, é discurso, mas é, acima de tudo, simbolismo. Quando falamos de ganhar ideias, a gente tem que ganhar ideias. Alguém que diz que quilombola não serve "nem para procriar", que as mulheres devem ganhar menos porque engravidam e que não irá demarcar nenhum centímetro de terra para índio, essa pessoa incita o ódio, incita a violência. E Bolsonaro tem um monte de seguidores... O presidente eleito não nos representa porque prega a xenofobia para com os nordestinos e nordestinas, contra as mulheres, contra os negros, contra a cidadania LGBT, e isso incita a violência. 2017 foi o ano que mais matou LGBT's , está claro, ele é um símbolo de violência.

Pergunta: Como observa a participação das mulheres brasileiras em cargos políticos ou de decisão?

Sandra Marrocos: Tenho muita sororidade para com as mulheres. Abro mão dos meus desejos íntimos e intimistas em nome das mulheres. Mulheres no poder como eu, como Estela Bezerra, como Jandira Feghali, como Manuela D’avila, como Luciana, de Pernambuco, como a governadora eleita Fátima Bezerra... Quando a gente tem um 
processo de construção e desconstrução que faz com que a gente tenha consciência que está ocupando um espaço de poder é muito bom. Agora, quando as mulheres vêm da história coronelista de ter pai político, marido político, e assumir os espaços de poder é muito desafiante, pois temos que ter a sororidade e o enfrentamento, porque não podemos usar uma palavra contra nós enquanto mulheres. Luto com todas as minhas forças para que mulheres assumam cargos políticos independente de partido político, elas devem estar lá, mulheres como nós que passamos por um processo de construção devemos conquistar mais mulheres. Nossa tarefa é garantir que as mulheres estejam lá.

Pergunta: Qual o papel da oposição no atual cenário político?

Sandra Marrocos: Resistência e luta! Uma resistência propositiva.

Pergunta: Qual a sua concepção sobre direita, esquerda e centro na política brasileira?

Sandra Marrocos: O centro dá um trabalho, pois Ciro Gomes está dando muito trabalho. Nesse momento, o povo da esquerda serviu para se fortalecer, esse momento todos vivenciamos um projeto de disputa de sociedade. Ficou mais prático de a esquerda se colocar, da direita se colocar, e do centro se perceber e ver para onde vai, pois essa história de centro é muito estranha, pois na política você tem que ter lado, ou você é esquerda ou direita. Nesse momento, a esquerda se vê e dialoga, e com as mulheres isso é muito mais fácil, fazer esse diálogo, a direita se vê e esse povo do centro que, na verdade, é direita vai ter que ter um prumo, vão ter que ver se vão aceitar essa loucura que é Bolsonaro ou lutar. Se está com eles ou conosco. Quando se tem um projeto de luta de governo e sociedade é muito mais fácil perceber essa divisão.

Pergunta: O que fará para o Brasil de amanhã? 
Sandra Marrocos: Tudo que estiver ao meu alcance, se a gente perder essa geração agora, a gente perde. Vamos para a década de 80, veja o que aconteceu, a década de 90 é uma década totalmente perdida, e a juventude de hoje são as crianças daquele tempo. Tem coisa mais bacana do que aquela ideia dos CAIC's, de Leonel Brizola? Era fantástica, era pra gente ter pego aquilo e não ter abandonado nunca. A gente perde uma geração todinha, a gente recupera ela no governo de Lula e inclusive hoje você tem, de fato, filhos e filhas do povo na universidade, onde nunca estiveram. Nossa tarefa hoje é resistir para que a gente não perca essa geração, se não eles não tem mais referencial, a que se perdeu, se perdeu, é a barbárie, a gente não pode deixar, estou prontinha para esta tarefa.

Pergunta: Rapidinhas. Um livro?

Sandra Marrocos: 100 anos de Solidão, de Gabriel Garcia Marquez. Todo Poder às Mulheres. O Conto da Aya.

Pergunta: Uma música?

Sandra Marrocos: Vitoriosa - Ivan Lins.

Pergunta: Uma frase?

Sandra Marrocos: Se fere nossa existência, seremos resistência.

Pergunta: Um sonho?

Sandra Marrocos: Acabar com a fome no mundo. 